\title{
Student Satisfaction with Experiential Learning in External Geriatrics and External Paediatrics
}

Lisa W. Christian OD, FCOVD, FAAO; School of Optometry and Vision Science, University of Waterloo, Waterloo, Ontario Tammy Labreche OD; School of Optometry and Vision Science, University of Waterloo, Waterloo, Ontario Patricia Hrynchak OD, MScCH(HPTE), FAAO; School of Optometry and Vision Science, University of Waterloo, Waterloo, Ontario Correspondence may directed to lisa.christian@uwaterloo.ca

tudents benefit from educational experiences which occur in the context of actual practice. ${ }^{1}$ Knowledge, skill and attitudes are more easily recalled when learning occurs in the same context as in which it is applied. ${ }^{1}$ Exposing students to patients with conditions help them to turn a basic understanding of the condition into a more complex mental model rich with nuances and variations in ways in which patient's present. ${ }^{2}$ Therefore, exposing students to learning opportunities in addition to a typical clinical setting prepares them optimally for practice with a richer set of experiences. ${ }^{1}$ Based upon social learning theory, students become "legitimate peripheral" participants watching and learning from the encounters. ${ }^{3}$

\begin{abstract}
T es étudiants bénéficient d'expériences d'éducation dans le contexte de la pratique réelle ${ }^{1}$. Il est plus facile Lde se rappeler des connaissances, des compétences spécialisées et des attitudes lorsque l'apprentissage se déroule dans le même contexte que celui où elles sont appliquées'. L'exposition des étudiants à des patients qui ont des problèmes les aide à transformer une compréhension fondamentale du problème en un modèle mental plus complexe, riche de nuances et de variations au niveau de la présentation des patients ${ }^{2}$. L'exposition des étudiants à des possibilités d'apprentissage en plus d'un contexte clinique type les prépare donc de façon optimale à exercer, dotés d'un ensemble plus riche d'expériences ${ }^{1}$. Compte tenu de la théorie de l'apprentissage social, les étudiants deviennent des participants « légitimes en périphérie » qui regardent et apprennent grâce à ces contacts ${ }^{3}$.
\end{abstract}

The external geriatrics and external paediatric services provided by the University of Waterloo, School of Optometry and Vision Science (UWOVS) program are two examples of this type of enhanced experiential learning. Third and fourth year clinical interns have the opportunity to participate in these services. In addition to optimizing learning, these educational experiences expose students to career options and styles of practice that they might not otherwise have considered. Having optometrists pursue these avenues of service provides a significant benefit for the communities within which they practice.

The external geriatrics service provides care to the geriatric population living in long term care facilities (LTC) or retirement dwellings. It is well known that the average age of the Canadian population is increasing. In $2013,15.3 \%$ of the Canadian population was over the age of 65 and by 2030 it is projected that approximately $25 \%$ of the population will be in this age group. The proportion of older seniors ( $>80$ years old) will also increase from $4.1 \%$ to $9.6 \%$ of the total population by 2045 or represent $39.4 \%$ of seniors. In $2011,7.9 \%$ of seniors were living in a retirement, (LTC) or health care facility. ${ }^{4,5}$ The impact of the overall increase in representation of seniors in the population means that there will be an increasing need to provide service for this population within retirement dwellings.

Vision impairment is 3 to 15 times higher in seniors who reside in a LTC facility or retirement home than seniors residing in the community. ${ }^{6}$ This is consistent with the higher prevalence of ocular disease in those residing in a LTC facility or retirement home. ${ }^{7}$ A study by Labreche et $\mathrm{al}^{8}$ of seniors residing in LTC facilities or retirement communities in the Waterloo region confirmed that the prevalence of AMD is higher (41.2\%) than published data for those in the general population over the age of 80 years of age (13.6\%). ${ }^{9}$ At a more basic level, it has been found that approximately $37 \%$ of those residing in a facility would benefit from suitable correction of refractive error. ${ }^{10}$

Visual impairment has been shown to lead to an increased 
risk of falls and fractures ${ }^{11}$ and to an increase in short-term mortality. ${ }^{12}$ Visual impairment also negatively impacts activities of daily living and leisure activities, decreases quality of life and is associated with increased risk of depression. ${ }^{12-14}$ Since health-related quality of life due to visual impairment is not worsened by a co-existing cognitive impairment, improvement of visual function could increase quality of life measures even for those multiply impaired individuals. ${ }^{15}$ Correction of refractive error leading to increased visual acuity alone improves quality of life scores and reduces symptoms of depression. ${ }^{6}$

There is evidence in the literature that LTC facilities are consistently underserviced with vision care. A recent survey of 196 LTC facilities in Quebec revealed that although 84\% of facilities enquired about vision upon admission, only $8.7 \%$ of facilities had a room available for eye exams on site. The vast majority (85.9\%) had access to an optometrist or ophthalmologist off-site. However, eye exams were not provided to all residents. For those that were assessed, it was not at the same frequency as practice guidelines recommend. ${ }^{16}$

This limited access to eye care may be due to the lack of willingness of optometrists to conduct eye exams in an external setting. A study of barriers for Canadian medical doctors choosing geriatrics as their specialty described that one barrier was insufficient exposure to the field of practice. It was suggested that exposure to the specialty early on in training and provision of sufficient clinical experience may translate into increased desire to practice geriatrics. Good role models and mentors were also key. ${ }^{17}$ It is reasonable to assume that optometry would be similar.

UWOVS provides complete oculo-visual assessments and follow-up care with therapeutic management, low vision rehabilitation, and access to optical services to 20 LTC facilities. Students in the third and fourth year of training are exposed to this unique clinical teaching environment. Aside from gaining greater comfort with implementation of different and portable assessment techniques and skills, students learn to assess patients and communicate more effectively with those with speech and/or cognitive impairments. They are also introduced to working collaboratively within a multiprofessional environment. Our intended outcome for this clinical experience is to produce practitioners with the knowledge and skills to willingly provide care to this expanding segment of our population.

In addition to the external geriatric program, UWOVS also has an external paediatric program which provides vision care to children from the age of 6 months to 12 years in the Kitchener-Waterloo area.

Vision disorders are common among the paediatric population in Canada; with an estimated $25 \%$ of children between the ages of 0-18 years affected. At 6 months, the average child can reach for and grasp a toy with one hand, sit up with support, and is cognitively aware of their surrounding environment making this an appropriate age for the first eye and vision examination. ${ }^{18,19}$ In addition, at 6 months of age, manifestations of strabismus, high refractive error, and anisometropia can be detected. ${ }^{20}$ While treatment varies depending on the severity these conditions, it should be initiated as soon as possible (when indicated). There is increased success when the condition is diagnosed and treated earlier rather than later in life. ${ }^{21}$ Delaying the onset of treatment can impair binocular interaction and/or acuity development, and may inhibit future perceptual, cognitive and social development. ${ }^{22,23}$ It is therefore recommended, that a child receives their first eye examination around 6 months of age. ${ }^{24}$

While research has shown that the prevalence of eye and vision disorders in children is significant, it is estimated only $5 \%$ of children between the ages of $0-4$ years receive a comprehensive vision examination. Based on these results, the UWOVS initiated an external pediatric program in 2004 to promote and provide paediatric vision care in the KitchenerWaterloo community.

UWOVS currently provides full vision examinations, round-table discussions and seminar presentations to three specific focus groups: elementary schools, public childhood educational centres, and under-serviced communities. Currently the program services over a dozen different facilities, and has seen over 1,000 children who had not previously received vision care. Between 2004 and 2014, the program performed 1,246 full eye exams at local elementary schools and found 283 children $(22.7 \%)$ who had a refractive, binocular vision and/or ocular problem. While UWOVS is making a difference in paediatric vision care within the KitchenerWaterloo community, more programs are needed to promote vision exams throughout the province of Ontario; with the ultimate goal of expansion throughout Canada. The UWOVS external paediatric program will hopefully serve as a model for other optometrists and optometry schools to encourage and provide pediatric vision care in their community.

So how do we know how well we are doing in educating optometrists to provide care for these special populations? The goal of optometric education is to produce optometrists with an entry level of proficiency in a defined set of competencies. ${ }^{25}$ The development of an optometry school curriculum includes planning content and structure, deciding on educational activities and assessing learners. A very important additional component is program evaluation. In program evaluation, 
information is gathered and used to make judgements about the value of the program which can lead to avenues for improvement. ${ }^{26}$ Different models can be used for program evaluation which can focus on various aspects of process and/or outcome. A popular model that focuses on the outcome of education is Kirkpatrick's model. ${ }^{26}$ This model has four levels of evaluation; reaction or satisfaction, learning, behaviour and results. ${ }^{26}$ We looked at learner satisfaction with experiential learning in the external geriatrics and paediatrics programs.

A pre-validated satisfaction survey was given to optometry students upon completion of their third year of the program. The students had an opportunity to participate in the external geriatric and paediatric service provision during the year. The survey included questions regarding clinical supervision, the learning environment, the working environment and the physical environment. Each category was assessed using a 6-point Likert scale and overall satisfaction of the program was rated on a scale of 0 to 100 . The results showed that students were satisfied with the supervision in the external programs. The learning, working and physical environment were less satisfactory as would be expected. LTC facilities and schools require adapting spaces for different purposes forcing the students to use modified techniques thereby enhancing their repertoire of skills. Next steps in our research will include determining if exposure to these experiences increases the probability that the services will be delivered by graduates in their own communities.

\section{References}

1. Mohanna K. Teaching made easy: A manual for health professionals. 3rd ed. New York, NY: Radcliffe Publishing, 2010.

2. Schuwirth L. Is assessment of clinical reasoning still the Holy Grail? Med Ed. 2009; 43:298-299.

3. Hodges BD, Kuper A. Theory and Practice in the Design and Conduct of Graduate Medical Education. Acad Med. 2012; 87:25-33.

4. Statistics Canada. Population projections: Canada, the provinces and territories, 2013 to 2063. 2015; http://www.statcan.gc.ca/pub/91-520-x/91520-x2014001-eng.htm. Accessed July 9, 2015.

5. Statistics Canada. Living arrangements of seniors. 2012; http://www12. statcan.gc.ca/census-recensement/2011/as-sa/98-312-x/98-312-x2011003_4eng.pdf. Accessed July 9, 2015.

6. Owsley C, et al. Effect of refractive error correction on health-related quality of life and depression in older nursing home residents. Arch Ophthalmol. 2007; 125: 1471-1477.

7. Eichenbaum JW, et al. The prevalence of eye disease in nursing home and non-nursing home geriatric populations. Arch Gerontol Geriatr. 1999; 28: 191-204.

8. Labreche T, Stolee P, McLeod J. An optometrist-led eye care program for older residents of retirement homes and long-term care facilities. Can Geriatr J. 2011; 14: 8-11.

9. CNIB and the Canadian Ophthalmological Society. The cost of vision loss in Canada. 2009; http://www.cnib.ca/eng/cnib\%20document\%20library/ research/covl_full_report.pdf. Accessed July 14, 2015.

10. Tielsch JM, et al. The prevalence of blindness and visual impairment among nursing home residents in Baltimore. N Engl J Med. 1995; 332: 1205-1209.
11. Black A, Wood J. Vision and falls. Clin Exp Optom. 2005; 88: 212-222.

12. Jung S, Coleman A, Weintraub NT. Vision screening in the elderly. J Am Med Dir Assoc. 2007; 8: 355-362.

13. Kelly M. Consequences of visual impairment on leisure activities of the elderly. Geriatr Nurs. 1995; 16: 273-275.

14. Dev MK, et al. Psycho-social impact of visual impairment on health-related quality of life among nursing home residents. BMC Health Serv Res. 2014; 14: 345 .

15. Elliot AF, McGwin Jr. G, Owsley C. Health-related quality of life and visual and cognitive impairment among nursing-home residents. Br J Ophthalmol. 2009; 93: 240-243.

16. The Canadian Association of Optometrists. Frequency of Eye Exams. 2013; https:/opto.ca/sites/default/files/cao_position_statement_frequency_of_ eye_examinations.pdf. Accessed August 15, 2015.

17. Diachun LL, Hillier LM, Stolee P. Interest in geriatric medicine in Canada: How can we secure a next generation of geriatricians? J Am Geriatr Soc. 2006; 54: 512-519.

18. Centers for Disease Control and Prevention. Important Milestones: Your Baby at Six Months. 2014; http://www.cdc.gov/ncbddd/actearly/milestones/ milestones-6mo.html. Accessed August 13, 2015.

19. White BL. The first three years of life. Englewood Cliffs, NJ: Prentice-Hall, Inc., 1975:77-102.

20. Scheiman MM, et al. Pediatric Eye and Vision Examination: Reference Guide for Clinicians. St. Louis, MO: American Optometric Association, 2002.

21. Williams C, et al. Amblyopia treatment outcomes after screening before or at age 3 years: follow up from randomised trial. BMJ. 2002; 324: 1549-51.

22. Packwood EA, et al. The psychosocial effects of amblyopia study. JAAPOS. 1999; 3:15-17.

23. Chua B, Mitchell P. Consequences of amblyopia on education, occupation, and long term vision loss. Br J Ophthalmol. 2004; 88:1119-21.

24. American Public Health Association. Policy Statement No. 20011 - Improving early childhood eyecare. 2001; http://www.apha.org/ policies-and-advocacy/public-health-policy-statements/policydatabase/2014/07/09/10/58/improving-early-childhood-eyecare. Accessed August 15, 2015.

25. Harden RM. Outcome-based education--the ostrich, the peacock and the beaver. Med Teach. 2007; 29: 666-71.

26. Frye AW, Hemmer PA. Program evaluation models and related theories: AMEE guide no. 67. Med Teach. 2012; 34:e288-99. 